\title{
Gonadotropin-Releasing Hormone (GnRH) Neuron in the Forebrain of Male Shiba Goat
}

\author{
Gustavo Oscar ZUCCOLILLI, Tomohiro HAMADA, \\ Masumi ICHIKAWA ${ }^{1)}$ and Yuji MORI \\ Laboratory of Veterinary Ethology, \\ The University of Tokyo, Bunkyo-ku, Tokyo 113, and \\ ${ }^{1)}$ Department of Anatomy and Embryology, \\ Tokyo Metropolitan Institute for \\ Neuroscience, Fuchu, Tokyo 183, Japan
}

\begin{abstract}
The GnRH neuron was investigated immunohistochemically in the hypothalamus and other diencephalic areas of mature male Shiba goats. Morphological characteristics and the distribution pattern of cell bodies immunoreactive to $\mathrm{GnRH}$ ( $\mathrm{GnRH}$-ir) as well as the projection of GnRH-ir fibers were examined in serial coronal sections ( $40 \mu \mathrm{m}$ thick) extending from the diagonal band of Broca to the mammillary complex in the rostro-caudal direction using a specific monoclonal antibody (LRH 13). The GnRH-ir cell bodies were classified morphologically into two subtypes, i.e. bipolar and multipolar, based on the number of processes. The distribution pattern of GnRH-ir cell bodies was strikingly similar in all the animals examined, and $51 \%$ of total immunoreactive neurons were found in a restricted region including the preoptic area, supraoptic nuclei and the vicinity of the organum vasculosum of the lamina terminalis. The major fiber projections were seen in the neurohemal organs, namely the median eminence and the organum vasculosum of the lamina terminalis. The GnRH fibers were also found in the mammillary complex and the habenular system but not in the amygdaloid complex.
\end{abstract}

Key words: GnRH neuron, Immunohistochemistry, Male goat.

( J. Reprod. Dev. 40: 19-25, 1994)

$\mathbf{G}$ onadotropin-releasing hormone $(\mathrm{GnRH})$ is considered to be a central determinant in the control of the hypothalamo-pituitary-gonadal axis which eventually governs reproductive function in mammals [1]. With immunohistochemical approaches the GnRH neuron has been extensively studied in several mammalian species such as the guinea-pig [2], golden-hamster [3], rat [4, 5], rabbit [6], human [7], baboon [8], ferret [7], bat [9], and sheep [10, 11]. Although in general the distribution patterns of $\mathrm{GnRH}$ neuron appear similar in all these species i.e. most cell bodies being located in

Accepted for Publication: September 2, 1993

Correspondence: $Y$. Mori the hypothalamus, a considerable interspeciesvariation has been reported for the proportion of GnRH neurons in various hypothalamic regions [12].

In ruminants much of the information about the anatomical array of the GnRH neuron has been obtained from sheep [13, 14] and goats [15]. These previous studies were, however, carried out mainly in female animals, and thus little information is available for the male [16]. The present study was therefore conducted to examine the morphology, distribution and connections of the GnRH neuron in the male goat. 


\section{Materials and Methods}

\section{Animals}

Three mature male Shiba goats (12-15 months old, 10-12 kg body weight) were from a closed colony kept in the Experimental Station for Animal Husbandry, the University of Tokyo (Iwama, Ibaraki).

\section{Immunohistochemistry}

The procedure was described in detail elsewhere [15]. Briefly, the animals were deeply anesthetized with pentobarbital and perfused bilaterally with $0.9 \%$ of saline solution followed by Zamboni's fixative [17]. The brain and attached pituitary gland were carefully removed from the cranium and trimmed down to a block. The block was then serially cut into coronal sections $40 \mu \mathrm{m}$ thick on a freezing microtome whereas the pituitary was cut in the sagittal plane. Every sixth section were immunostained with a monoclonal antibody (LRH 13) that recognized a common amino acid sequence of the GnRH molecule including the binding site around the serine-tyrosine region and with constant affinity $\left(0.134 \times 10^{9} \mathrm{M}^{-1}\right)$ [18]. Horseradish peroxidase activity was demonstrated with $3,3^{\prime}$ diaminobenzidine tetrahydrochloride as a chromogen and a commercial ABC kit (Vector Laboratories, Burlingame, CA, USA). The sections were mounted, dehydrated and coverslipped. Every second section was stained with cresyl violet. In all sections the morphology and distribution of GnRH-ir neurons were examined by light microscopy.

\section{Results}

\section{Morphology of GnRH cell bodies}

The GnRH-ir cell bodies were found to be scattered and isolated from each other with the exception of the region of high concentration where they resided in close association and formed clusters. The cell body size averaged $27 \times 18 \mu \mathrm{m}(\mathrm{n}=100$ in each animal), and the predominant cell type was bipolar (58\%), as shown in Fig. 1. One of the two processes of the bipolar cells was usually thicker than the other, and a dilatation was often seen near the cell body. On the other hand, the remaining $42 \%$ of $\mathrm{GnRH}$-ir cell bodies were classified as multipolar. The contour of the soma appeared smooth in most of the GnRH-ir neurons, though a considerable proportion of them had a spiny or thorny appearance.

\section{Distribution of the GnRH cell bodies}

The main population of $\mathrm{GnRH}$-ir cell bodies was located in the rostral part of the hypothalamus as shown in Fig. 2. The GnRH-ir cell bodies were dispersed over several nuclei or areas including
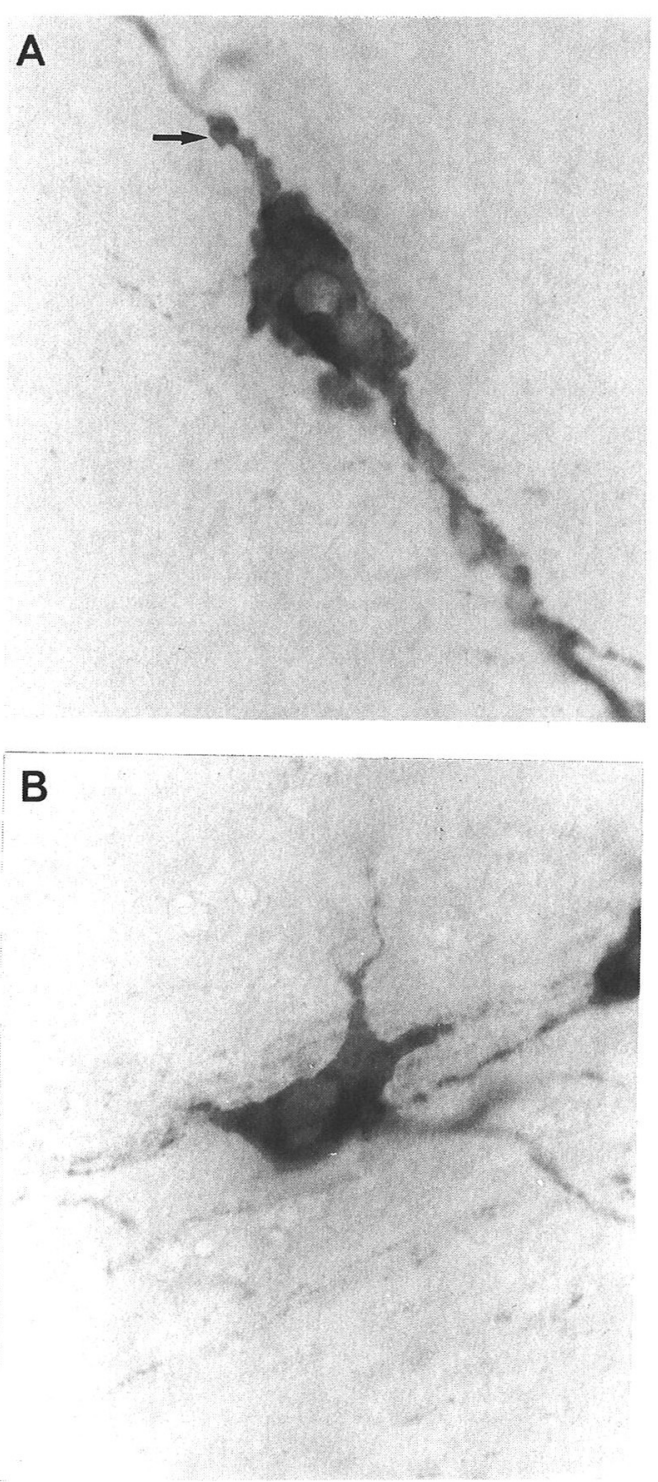

Fig. 1. Representative microphotos $(200 \times)$ of two morphological subtypes of $\mathrm{GnRH}$-ir cell body, A) bipolar subtype having 2 processes with one of them showing a dilatation (arrow), B) multipolar subtype with more than 3 processes emerging from the cell body. 


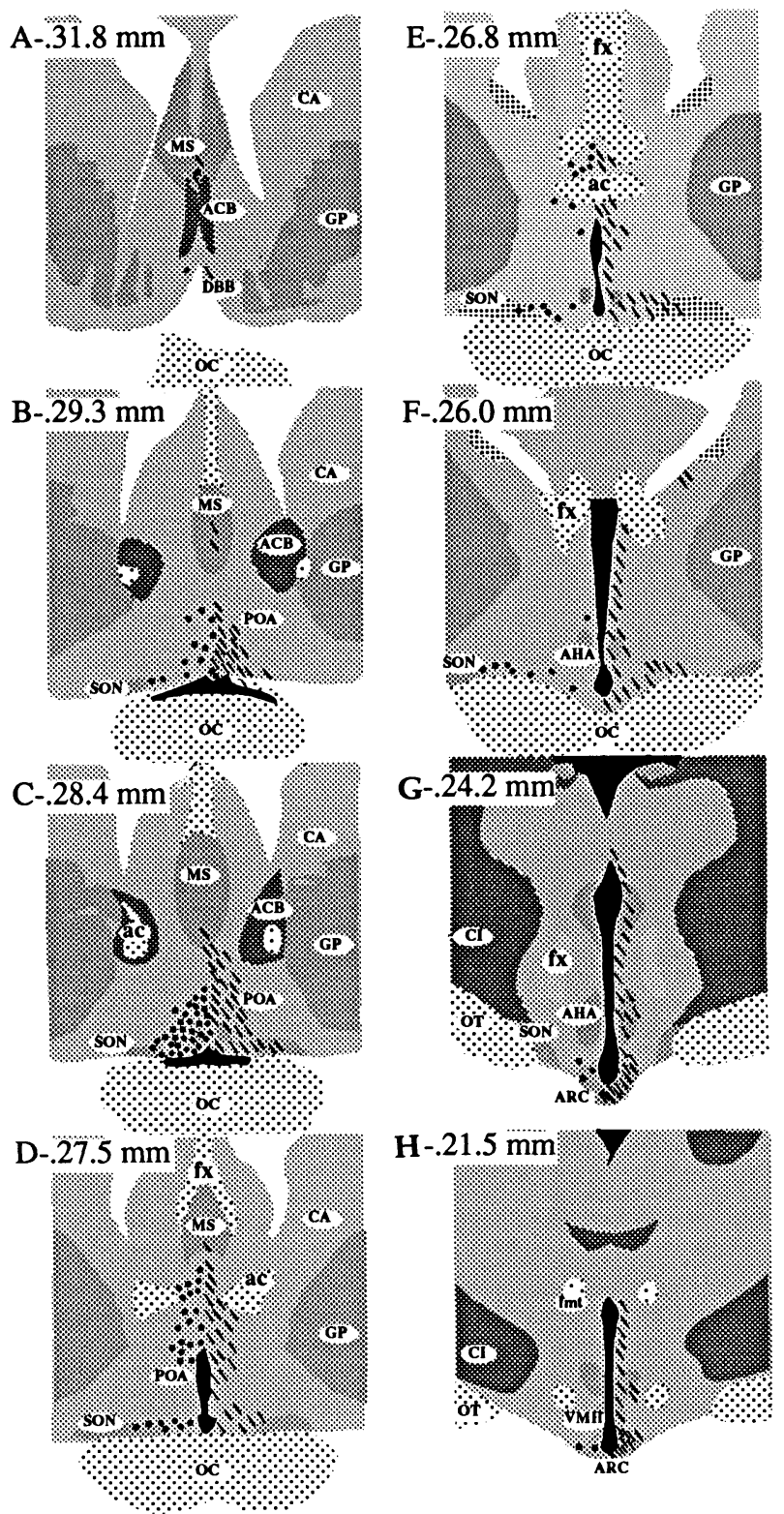

Fig. 2. Distribution pattern of the GnRH-ir cells (solid circles) and fibers (solid lines) in the coronal drawings of the goat hypothalamus on the stereotaxic coordinates. The right side of each illustration shows $\mathrm{GnRH}$-ir fibers, and the left, cell bodies. ac, anterior ommissure; ACB, septal accumbens nuclei; $\mathrm{AHA}$, anterior hypothalamic area ; $A R C$, arcuate nuclei ; $C A$, caudate nuclei; $C I$, internal capsule; $\mathrm{DBB}$, diagonal band of Broca; $\mathrm{fx}$, fornix; GP, globus pallidus; MS, medial septal area; fmt, mammillothalamic tract; $O C$, optic chiasm; OT, optic tract; POA, preoptic area; SON, supraoptic nuclei; $\mathrm{VMH}$, ventromedial hypothalamic nuclei. the preoptic area (POA), supraoptic nuclei (SON), medial septal area (MS) and the medial preoptic area (MPOA), which altogether covered approximately $80 \%$ of the total number of GnRH-ir neurons in the forebrain. Moreover, $51 \%$ of the total GnRH-ir cell population were concentrated in a restricted part of the POA, less than $1.5 \mathrm{~mm}$ thick in the rostro-caudal direction, surrounding the organum vasculosum of the lamina terminalis (OVLT) (Fig. 2 B, C). From this area the population of GnRH-ir cell bodies extended in two projections along which the number of cell bodies gradually decreased. The rostral extension reached the MS, between the accumbens nuclei and the horizontal limb of the diagonal band of Broca (Fig. $2 \mathrm{~A}$ ), which represented less than $2 \%$ of the total number of GnRH-ir cell bodies. The caudal projection extended towards the medial basal hypothalamus including the arcuate nuclei (ARC), which accounted for $6 \%$ of the GnRH-ir cell bodies. No neuron was found in the mammillary complex (MC).

\section{GnRH-ir projection fibers}

Immunopositive fibers (processes and nerve terminals) were found mainly in the median eminence (ME) and the OVLT, and secondarily in the habenular system and the MC. The greatest concentration was widely distributed in the $\mathrm{ME}$, and a dense network of immunoreactive fibers was seen around the primary capillaries of the portal vessel system in the palisade zone of ME (Fig. 3). The rostral part of the ME was the main area of receiving fibers, whereas a considerable number of immunoreactive fibers were also observed in the middle and caudal parts. GnRH-ir fibers were found running through the pituitary stalk and present within the neural lobe of the pituitary gland. These fibers ended in close contact with the cells of the intermediate lobe, and at minor proportion in the vicinity of the capillary vessels of the inferior hypophyseal artery in the caudal-dorsal region of the neural lobe.

The GnRH-ir fibers in the premammillary complex were located close to the midline running within the periventricular zone to the caudal-ventral part of the third ventricle. Another group of fibers was made evident in connection with the habenular system traveling in the stria habenularis thalamus. 


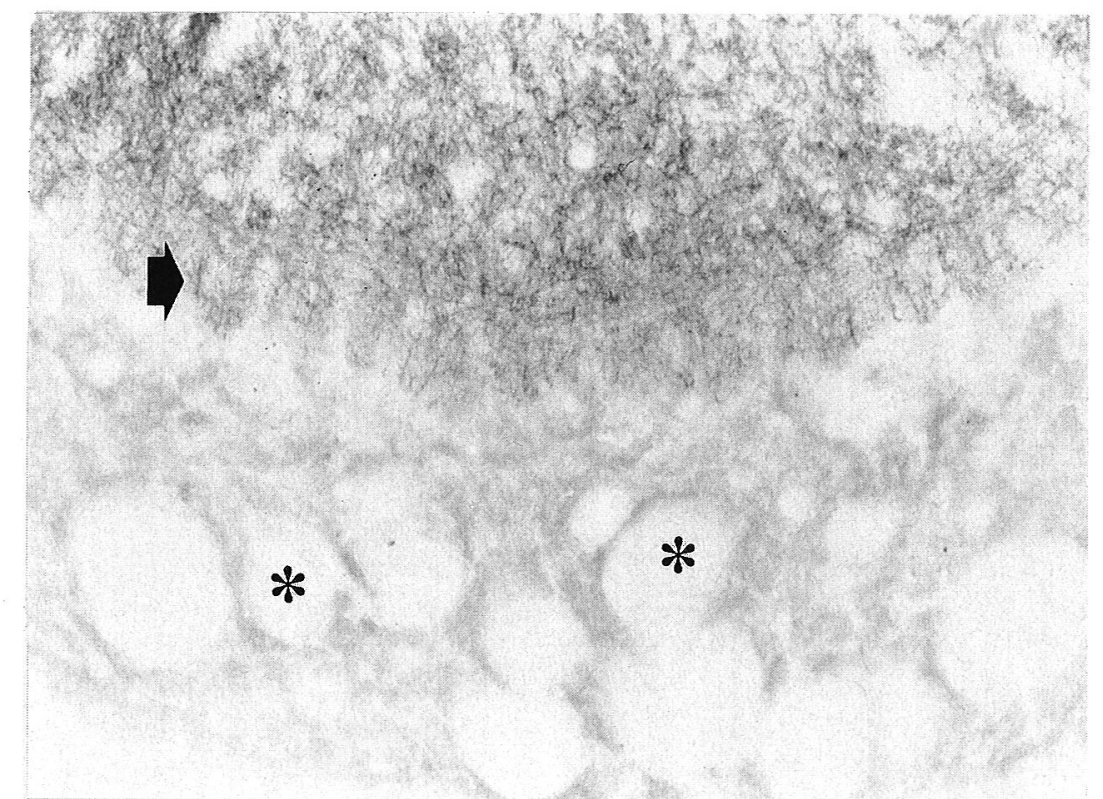

Fig. 3. Microphoto $(20 \times)$ of the ME. The immunoreactive material surrounded the capillary vessels of the palisade zone of the ME (arrow). The asterisks indicate the portal vessels leading into the infundibular part of the pituitary gland.

\section{Immunoreactive structures in the OVLT}

In the OVLT an interesting structure was found which consisted of GnRH-ir cells and fibers. It appeared as a network of GnRH-ir fibers intercalated with various numbers (4-14 cells) of GnRH-ir cell bodies at the ventral part of the OVLT, which forms the roof of the optic recess of the third ventricle as shown in Fig. 4.

\section{Discussion}

The overall distribution pattern of the GnRH-ir cell bodies and fibers in the male Shiba goat was virtually identical to that seen in the doe [15], and similar to other mammalian species investigated so far, including another seasonally breeding ruminant i.e. sheep $[7,10,14,19]$. The principal area containing the GnRH-ir neuron was the POA at the level of the OVLT in the rostro-caudal direction. The present results were in agreement with our previous report on the female Shiba goat [15], and allowed us to classify this species among those which have a predominant population of GnRH neurons in the rostral hypothalamus, e.g. sheep [10] (ruminant), rat [1, 5] and golden hamster [3] (rodent). In these species the greatest number of GnRH cell bodies are located in the POA and MPOA, while much smaller proportion of cells are found in the ventro-medial hypothalamus. However, there are species which show rather an opposite distribution pattern of the GnRh neuron, for example man, monkey (primate) and ferret (carnivore), in which GnRH neurons are restricted mainly to the medial basal hypothalamus including the ARC [7]. Although numerous factors would have been involved in this diversified distribution pattern of GnRH neurons, the most conspicuous development of the visual system in primates and carnivores might be one of the phylogenic change responsible for it.

The rostral extension of the GnRH system, i.e. the presence of a few GnRH-ir cells and fibers in the MS, might represent a remainder of the ontogenic migration from the olfactory placode during the fetal period which has been demonstrated in other species [20,21]. As for the caudal extension of the GnRH system, behavioral impli- 

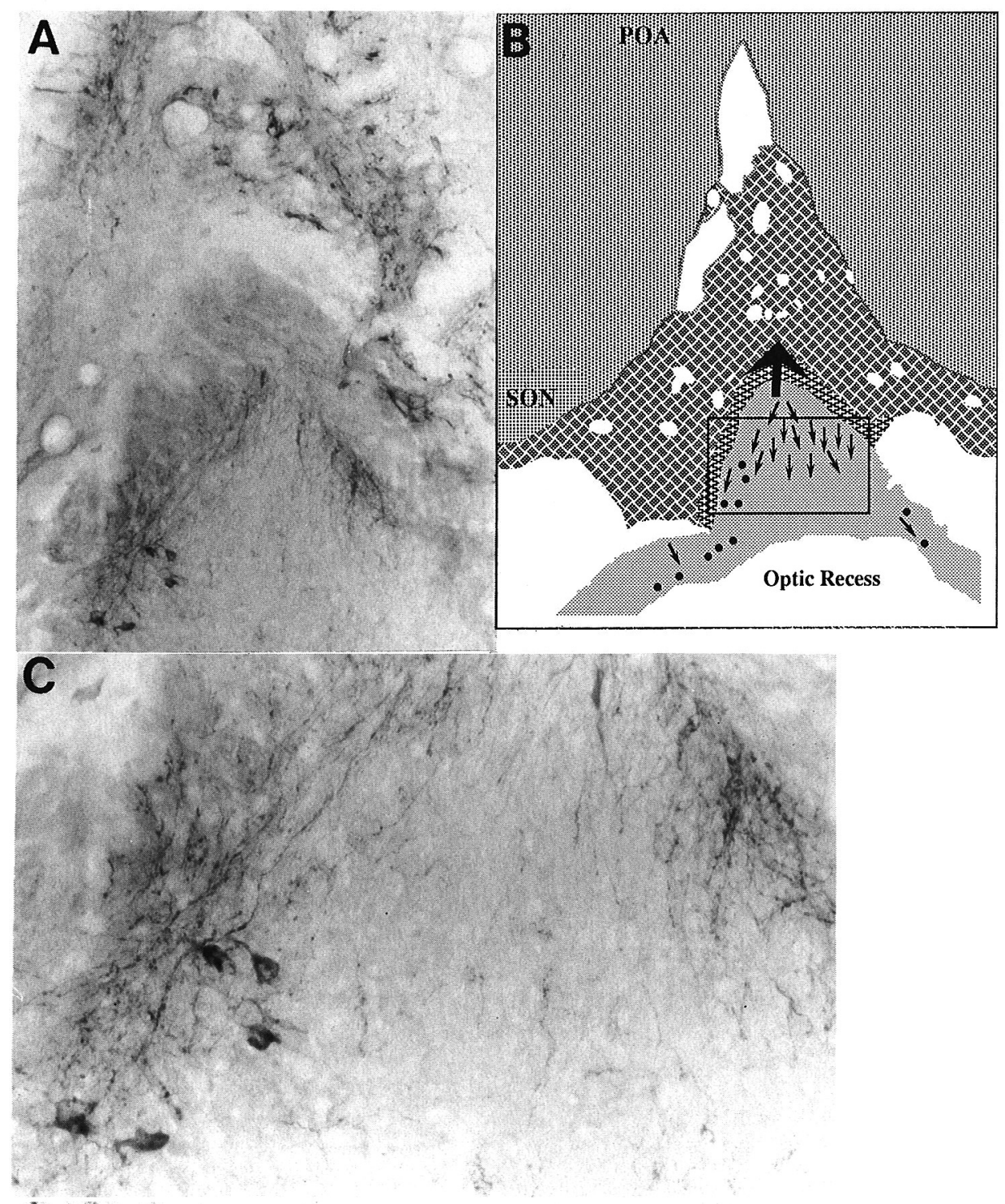

Fig. 4. A) Microphoto $(20 \times)$ of the OVLT of a male Shiba goat. B) The schematic illustration showing the anatomical structure of the OVLT. The arrow indicates the dorsal or vascular part of the OVLT. The ventral part contains abundant GnRH-ir fibers (small arrows) and some cell bodies (solid circles). C) Greater magnification $(100 \times)$ of the ventral part of the OVLT (shown as the square in B) demonstrating the GnRH-ir Structures. POA, preoptic area; SON, supraoptic nuclei.

cations have been postulated in rodents [22].

The projection of GnRH fibers through the pituitary stalk and neural lobe of the gland has been described in other species such as man, monkey and ferret $[7,23]$, although it is still unclear what function the GnRH system may have in connection with the cells of the pituitary intermediate lobe and around the capillary vessels of the distal part of the neural lobe. In mammals these GnRH fibers are considered to represent a primitive phylogenic remainder with rather negligible function from the well developed system in lower vertebrates such as fishes [24, 25].

Perhaps, one of the most intriguing questions arising from the present study concerns the role of the GnRH-ir neuron in the OVLT. The structure of goat OVLT has many similarities to that described in sheep [19], and in mammalian species 
studied so far GnRH-ir fibers have been reported to reach the OVLT [7]. However, this is probably the first report demonstrating the presence of GnRH-ir cell bodies within the OVLT. Moreover a number of $\mathrm{GnRH}$-ir fibers were found to be in close contact with the ependymal layer of the third ventricle. These features suggest that the GnRH are released from the OVLT into the cerebrospinal fluid (CSF) and thereby play a physiological roles in the ME after being uptaken by the tanycyte system as an alternative or accessory pathway [26, 27]. However, further inferences about the special configuration of the OVLT in ruminants as well as the relationship between the GnRH network and the third ventricular CSF system must await more detailed study including electron microscopic as well as physiological approaches.

\section{Acknowledgements}

The authors thank Dr. K. Wakabayashi, Gunma University, and Dr. M. K. Park, University of Tokyo, for their generous gift of LRH 13 monoclonal antibody. We are also indebted to Professor M. Takahashi, University of Tokyo, for providing GOZ with the opportunity to study in Japan. This work was supported partly by grants from the Ministry of Education, Science and Culture, Japan.

\section{References}

1. Thiery J-C, Martin GB. Neurophysiological control of the secretion of gonadotrophin releasing hormone and luteinizing hormone in the sheep. A review. Reprod Fertil Dev 1991; 3: 137-173.

2. Barry J, Dubois MP, Poulain P. LRF producing cell of the mammalian hypothalamus. Z Zellforsch Mikrosk Anat 1973; 146: 351-366.

3. Jennes L, Stumpf WE. LHRH system in the brain of golden hamster. Cell Tissue Res 1980; 209: 239256.

4. Burchanowsky BJ, Sternberger LA. Improved visualization of luteinizing hormone releasing hormone pathways by immunocytochemical staining of thick vibratome sections. J Histochem Cytochem 1980; 28: 361-363.

5. Kawano M, Daikoku S. Immunohistochemical demonstration of LHRH neurons and their pathways in the rat hypothalamus. Neuroendocrinology 1981; 32: 179-186.

6. Foster WG, Younglai EV. An immunohistochemical study of the GnRH neuron morphology and topography in the adult female rabbit hypothalamus. Am J Anat 1991; 191: 293-300.

7. King JC, Anthony ELP. LHRH neurons and their projections in humans and other mammals: Species comparisons. Peptides 1984; 5 (suppl 1): 195207.

8. Marshall PE, Goldsmith PC. Neurosecretory and neuroendocrine $\mathrm{GnRH}$ pathways in the hypothalamus and forebrain in baboon. Brain Res 1980; 193: 353-372.

9. King JC, Anthony ELP, Gustafson AW, Damassa DA. Luteinizing hormone-releasing hormone (LH$\mathrm{RH}$ ) cells and their projections in the forebrain of the bat Myotis lucifugus lucifugus. Brain Res 1984; 298: 289-301.
10. Caldani M, Batailler $\mathbf{M}$, Thiery J-C, Dubois MP. LHRH immunoreactive structures in the sheep brain. Histochemistry 1988; 89: 129-139.

11. Advis JP, Kuljis RO, Dey G. Distribution of luteinizing hormone releasing hormone (LHRH) content and total LHRH-degrading activity (LHRH-DA) in the hypothalamus of ewe. Endocrinology 1985; 116: 2410-2418.

12. Nozaki M, Tsukahara T, Kobayashi H. Neuronal system producing LHRH in vertebrates. In: Ochiai et al. (eds.), Endocrine Correlates of Reproduction. Japan Scientific Societies Press. Springer, Tokyo, 1984; 3-27.

13. Lehman MN, Robinson JE, Karsch FJ, Silverman AJ. Immunocytochemical localization of luteinizing hormone-releasing hormone (LHRH) pathways in the sheep brain during anestrus and in the midluteal phase of the estrous cycle. J Comp Neurol 1986; 244: 19-35.

14. Polkowska J. Immunohistochemistry of luteinizing hormone releasing hormone (LHRH) and gonadotrophic hormones in the sheep after deafferentation of the hypothalamus. Cell Tissue Res 1981; 220: 637-649.

15. Hamada T, Shimizu T, Ichikawa M, Mori Y. Immunohistochemical study on gonadotropin-releasing hormone neurons in the Shiba goat brain. $J$ Reprod Dev 1992; 38: 133-142.

16. Dees WL, Sorensen AM Jr, Kemp WM, McArthur NH. Immunohistochemical localization of gonadotrophin-releasing hormone $(\mathrm{GnRH})$ in the brain and infundibulum of the sheep. Cell Tissue Res 1981; 215: 181-191.

17. Zamboni L, Martino D. Buffered picric acid paraformaldehyde: a new rapid fixative for electron microscopy. J Cell Biol 1967; 35: 148A. 
18. Park MK, Wakabayashi K. Preparation of a monoclonal antibody to common amino acid sequence of LHRH and its application. Endocrinol Japon 1986; 33: 257-272.

19. McKinley MJ, Denton $M$, Leventer M, Penschow J, Weisinger RS, Wright RD. Morphology of the organum vasculosum of the lamina terminalis (OVLT) of the sheep. Brain Res Bull 1983; 11: 649657.

20. Ronnekleiv OK, Resko JA. Ontogeny of gonadotropin-releasing hormone-containing neurons in early fetal development of rhesus macaques. Endocrinology 1990; 126: 498-511.

21. Scott DE, Krobisch Dudley G, Gibbs FP, Brown GM. The mammals median eminence. In: Knigge, Scott, and Weindl (eds.), Brain Endocrine Interaction: Median Eminence: Structure and Function. International Symposium on Brain-Endocrine Interaction. Munich. Aug. 2-3 1971. New York, 1972; 35-49.

22. Schwanzel-Fukuda M, Pfaff D. Origin of luteinizing hormone releasing hormone neurons. Nature 1989; 338: 161-163.
23. Anthony ELP, King JC, Stopa EG. Immunocytochemical localization of luteinizing hormone releasing hormone in the median eminence, infundibular stalk and neurohypophysis. Cell Tissue Res 1991; 236: 5-14.

24. Dubois MP, Billard R, Breton B, Peter RE. Comparative distribution of somatostatin, LH-RH, nerophysin, and $\beta$ endorphin in the rainbow trout: an immunohistochemical study. Gen Comp Endocrinol 1979; 37: 220-232.

25. Dufour S, Pasqualini C, Kerdelhue B, Fontaine YA. Presence and distribution of radioimmunoassayable LHRH in the European eel, Anguilla anguilla. Neuropeptides 1982; 3: 159-171.

26. Knigge KM, Silverman AJ. Anatomy of the endocrine hypothalamus. In: Knobil and Sawyer (eds.), Handbook of Physiology: Endocrinology, IV. 1. American Physiological Society, Washington, DC, 1974; 1-32.

27. Shivers BD, Harlan RE, Hejtmancik JF, Conn PM, Pfaff DW. Localization of cells containing LHRHlike mRNA in rat forebrain using in situ hybridization. Endocrinology 1986; 118: 883-885. 